\title{
IT Service Management and IT Automation
}

\section{Methods and Models for Efficient IT Operations}

\section{DOI 10.1007/s12599-010-0136-2}

\section{The Authors}

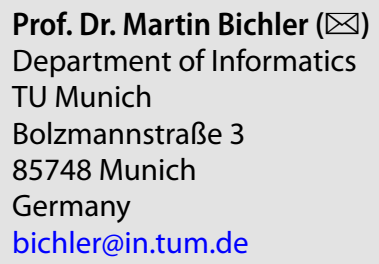

Prof. Dr. Martin Bichler ( $\varangle$ )

Department of Informatics

TU Munich

Bolzmannstraße 3

85748 Munich

Germany

bichler@in.tum.de

\section{Dr. Kamal Bhattacharya \\ IBM T.J. Watson Research Center \\ 19 Skyline Drive \\ Hawthorne, NY 10532 \\ USA \\ kamalb@us.ibm.com}

Published online: 2010-12-09

This article is also available in German in print and via http://www. wirtschaftsinformatik.de: Bichler $M$, Bhattacharya K (2010) IT-ServiceManagement und IT-Automation. Methoden und Modelle für effizienten IT-Betrieb. WIRTSCHAFTSINFORMATIK. doi: 10.1007/s11576-0100252-0.

(c) Gabler Verlag 2010
Over the last decade IT organizations have seen a significant increase in their service management cost by at the same time constant spent in capital expenses. Cost cutting in today's economy is high on the CIO's agenda, however the strategic importance of IT demands rapid deployment of new services to strengthen the enterprises competitiveness in the market. The root-causes of rising operational costs are related to the challenges of provisioning new services in a standardized way with highly automated service management processes that could enable gains from the economies of scale from an operational perspective.

The recent trend of growing Infrastructure, Platform, and Software as a Service (IaaS, PaaS, SaaS) offerings, such as Google App Engine, Salesforce.com, or Amazon Web Services has led the way in demonstrating standardization and highly efficient service management processes on the basis of rather homogenized environments. Enterprise data centers are however different. Today's enterprise data centers consist of a heterogeneous deployment base ranging from legacy mainframe environments to complex ERP systems to Intel based scale out systems, not to forget a plethora of infrastructure support devices such as networking infrastructure. Managing complex heterogeneous IT environments, albeit the increasing adoption of IT service management frameworks such as ITIL or CobiT is still largely manual at the end-points.

Up until now, little academic literature deals with effective processes for IT service operations. Compared to established areas in IS and operations management such as data engineering or production and inventory management, IT service management does not yet have a solid body of methods and quantitative models for the management and automation of IT service operations. The business and information systems engineering community is well positioned to address such research challenges.

In this special issue we want to address topics in this emerging field. We have received 15 submissions for the special issue from an international set of authors. Of these papers, after up to three rounds of reviews, we selected two research papers that each satisfied three criteria: (i) be rigorous from a technical standpoint, (ii) be interesting from an industry standpoint, and (iii) make a substantial and original contribution. In addition, we included a state-of-the-art paper on method support for information requirements analysis of analytical information systems. An interview with Doug King, Vice President at IBM, provides an overview of general trends in industry practice.

Achieving high quality standards was only possible due the active involvement of the BISE editorial board and a number of ad hoc referees. Special thanks go to Schahram Dustdar (Technical University of Vienna), Alfons Kemper (TU Munich), Robert Klein (University of Augsburg), Dieter Kranzlmüller (Ludwig Maximilian University of Munich), and Thomas Setzer (TU Munich).

\section{Contents}

In the first paper, Mauricio Marrone and Lutz Kolbe from the University of Göttingen present the results of an international survey of 491 firms on the benefits of the IT Infrastructure Library (ITIL). They want to understand, which challenges and benefits are perceived by an increasing adoption of ITIL. Their results indicate that as more and more ITIL processes are implemented, the perception of challenges decreases and the realized benefits increase. The authors discuss implications of their study for practice and research in this field.

While many of the technical questions of SaaS have received a great deal of attention in the recent years, the economics of such markets are much less understood. In the 
second paper, Arne Katzmarzik from the University of Augsburg analyses product differentiation for SaaS markets. He introduces a model to define the optimal granularity of services, in order to maximize revenue. The author also includes reproduction costs in their model, and show that those can have a significant impact on the granularity and profits of services.

The state-of-the-art paper by Florian Stroh, Robert Winter, and Felix Wortmann focuses on requirements engineering for analytical information systems. The authors evaluate current practices and discuss necessary methods support in this area. They highlight the need for further research on information requirements elicitation, validation, and management.

The special issue also contains an interview with Doug King from IBM on the impact of virtualization and cloud computing on IT service management. Doug King is a Vice President at IBM and currently serves as a Client Executive for Transition \& Transformation for large IBM outsourcing clients. He was previously responsible for IT optimization programs implementation in the IBM Global Account. In this interview, he comments on virtualization and data center consolidation, new business models, and the adoption of IT service management standards in the industry.

\section{Conclusions}

The mission of BISE is to publish high quality research in business and information systems engineering. IT service management is an emerging area and highly relevant to IS practitioners and researchers as well. Our contention is that this special issue on IT service management and IT automation demonstrates high quality work in this area; our aim is to make BISE a leading venue for such work.

Martin Bichler

Kamal Bhattacharya 